\title{
Использование магнитных наночастиц в устройствах управления ТГц излучением
}

\author{
Д.М. Ежов, Е.С. Савельев, Е.Д. Фахрутдинова, В.А. Светличный \\ Томский государственный университет, Томск, 634050, Ленина, 36 \\ тел./факс: +7 (3822) 531-591, эл.nочта: ezhov_dm@mail.ru
}

DOI $10.34077 /$ RCSP2021-53

Для эффективного применения ТГц излучения, необходимы устройства для управления его параметрами. К настоящему времени, существует несколько работ, демонстрирующих использование внешнего магнитного поля для управления жидкостными ТГц фильтрами $[1,2]$. В данных работах рассматриваются фильтры на основе дисперсий магнитных наночастиц - феррофлюидов. Для достижения высоких коэффициентов затухания при переключении таких модуляторов обычно требует создание значительных оптических трасс [3], что приводит к снижению начального пропускания фильтра. Другим перспективным подходом в создании устройств для модуляции ТГц излучения, является использование нанокомпозитных поляризационных фильтров, сформированных с помощью магнитного поля [4].

В ходе работы, нами были созданы и исследованы модуляторы ТГц излучения этих двух типов. Были исследованы пленочные поляризационные фильтры на основе магнитомягких субмикронных частиц сплава

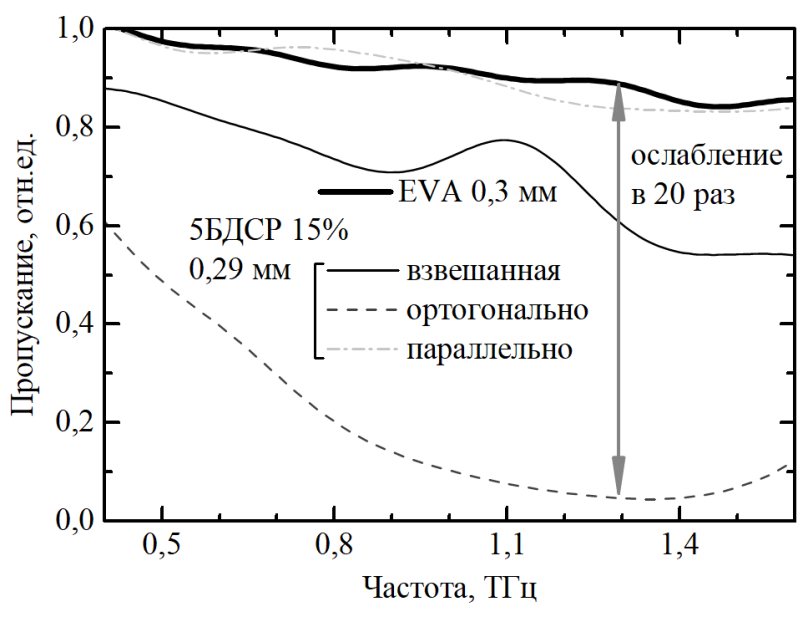
5БДСР или наночастиц $\mathrm{Fe}$, полученных электровзрывом, или импульсной лазерной абляцией. Магнитные частицы осаждались в присутствии постоянного магнитного поля в полимерную матрицу на основе фторопласта Ф-42 или этиленвинилацетата (EVA) [5]. Доля частиц к массе полимерной матрицы варьировалось от единиц до $15 \%$. Спектры пропускания лучших плёнок, полученных на основе EVA, приведены на рисунке сверху справа.

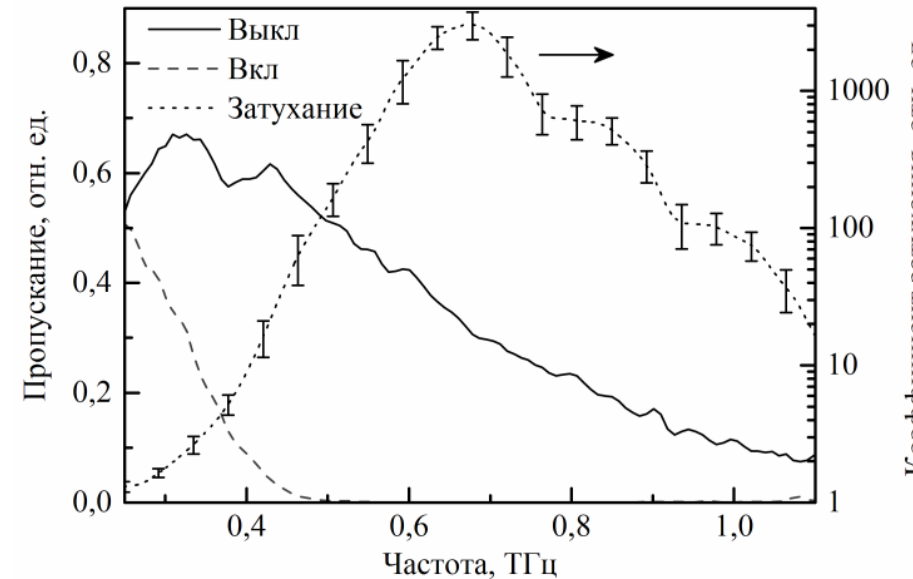

Был разработан и протестирован образец жидкостного фильтра, способного неселективно управлять интенсивностью излучения в диапазоне $0,4-1,4$ ТГц. Фильтр представляет собой 10 мм кювету с $5 \%$ дисперсий частиц 5БДСР в масле $80 \mathrm{~W}-90$, помещенную на пути ТГц излучения, внутри скрещенной пары катушек Гельмгольца. Созданный образец фильтра позволяет достигать коэффициента затухания вплоть до 35 дБ, как показано на рисунке слева, что сравнимо с традиционно выпускаемыми фильтрами. Автоматическая система запуска и перемешивания делает работу фильтра повторяемой, даже при многократной смене состояний открыт/закрыт фильтра.

Простота в реализации и дешевизна производства рассмотренных фильтров демонстрируют перспективность использования магнитных частиц для управления ТГц излучением.

Работа поддержана Российским научным фондом (РНФ) грант № 18-19-00268.

\section{Лumepamypa}

[1] M. Shalaby et al. // Appl. Phys. Lett. 2014. Vol.105, №15. P.151108.

[2] X. Liu et al. // J. Phys. D. Appl. Phys. 2018. Vol.51, №10. P.105003-105004.

[3] S. Chen et al. // Opt. Express. 2014. Vol.22, №6. P.6313-6321.

[4] D. Fragouli et al. // ACS Appl. Mater. Interfaces. 2014. Vol. 6, № 6. P. 4535-4541.

[5] D.M. Ezhov et al. // Proc. SPIE. 2020 Vol.11582. 6 p. 